\title{
Wisata Desa dan Desa Wisata
}

\author{
Bagus Sudibya
}

\begin{abstract}
Village tourism in Indonesia is known as desa wisata which in English means tourism village. Gramatically the right one is the village tourism. That is why the two terms (wisata desa and desa wisata) is used synonimously in Indonesian context. This qualitative study found that the substance is that the village tourism is a business run by local villagers. So that, such kind of tourism is the one with the basic of community-based tourism or CBT. In Bali, the tourism itself as well as the CBT is a practice of paradigm which is popularly known as tri hita karana or THK. THK itself is a very basic concept in Bali which includes the relationships among God (parhyangan), people (pawongan), and environment (palemahan). The success of the village tourism depends on the succes of the THK implementation in such a tourism.
\end{abstract}

Keywords: village tourism, villagers, community-based tourism.

\section{PENDAHULUAN}

Wisata desa adalah salah satu kegiatan kepariwisataan yang menawarkan keseluruhan suasana yang menonjolkan keaslian desa seperti pemandangan alam desa yang indah, kuliner, cenderamata, homestay dan sebagainya (http://www.berdesa.com/apa-beda-desa-wisata-dan-wisata-desa). Wisata desa secara sederhana dapat dikatakan sebagai kegiatan mengajak wisatawan untuk berkunjung ke desa, melihat dan mempelajari keaslian desa sesuai dengan keunikan dan potensi desa yang dimilikinya.

Sementara mengacu pada Laporan Akhir Kajian Pengembangan Desa di DIY tahun 2014, pengertian desa wisata dapat diuraikan sebagai berikut.

1) Suatu bentuk integrasi antara atraksi, akomodasi, dan fasilitas pendukung yang disajikan dalam suatu struktur kehidupan masyarakat yang menyatu dengan tata cara dan tradisi yang berlaku.

2) Suatu wilayah pedesaan yang memiliki keunikan dan daya tarik yang khas (baik berupa daya tarik/keunikan fisik lingkungan alam pedesaan maupun 
kehidupan sosial budaya kemasyarakatan), yang dikelola dan dikemas secara alami dan menarik dengan pengembangan fasilitas pendukung wisata dalam suatu tata lingkungan yang harmonis dan pengelolaan yang baik dan terencana Sehingga daya tarik pedesaan tersebut mampu menggerakkan kunjungan wisatawan ke desa tersebut, serta menumbuhkan aktifitas ekonomi pariwisata yang meningkatkan kesejahteraan dan pemberdayaan masyarakat setempat.

3) Definisi Desa Wisata lainnya adalah: Village Tourism, where small groups of tourist stay in or near traditional, often remote villages and learn about village life and the local environment. Terjemahan bebas: Wisata pedesaan di mana sekelompok kecil wisatawan tinggal dalam atau dekat dengan suasana tradisional, sering di desa-desa yang terpencil dan belajar tentang kehidupan pedesaan dan lingkungan setempat.

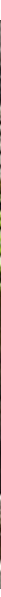

\section{PEMBAHASAN}

Desa Wisata dalam konteks wisata pedesaan adalah aset kepariwisataan yang berbasis pada potensi pedesaan dengan segala keunikan dan daya tariknya yang dapat diberdayakan dan dikembangkan sebagai produk wisata untuk menarik kunjungan wisatawan ke lokasi desa tersebut. Mengutip pernyataan Hadiwijoyo (2012), desa wisata memiliki kriteria sebagai berikut.

1. Aksesbilitasnya baik, sehingga mudah dikunjungi wisatawan dengan menggunakan berbagai jenis alat transportasi. 
2. Memiliki objek-objek menarik berupa alam, seni budaya, legenda, makanan lokal, dan sebagainya untuk dikembangkan sebagai objek wisata.

3. Masyarakat dan aparat desanya menerima dan memberikan dukungan yang tinggi terhadap desa wisata serta para wisatawan yang dating ke desanya.

4. Keamanan di desa tersebut terjamin.

5. Tersedia akomodasi, telekomunikasi, dan tenaga kerja yang memadai

6. Beriklim sejuk atau dingin

7. Berhubungan dengan objek wisata lain yang sudah dikenal oleh masyarakat luas.

Masyarakat lokal berperan penting dalam pengembangan desa wisata karena sumber daya dan keunikan tradisi dan budaya yang melekat pada komunitas tersebut merupakan unsur penggerak utama kegiatan desa wisata. Di lain pihak, komunitas lokal yang tumbuh dan hidup berdampingan dengan suatu objek wisata menjadi bagian dari sistem ekologi yang saling kait mengait. Keberhasilan pengembangan desa wisata tergantung pada tingkat penerimaan dan dukungan masyarakat lokal (Wearing, 2001). Masyarakat lokal berperan sebagai tuan rumah dan menjadi pelaku penting dalam pengembangan desa wisata dalam keseluruhan tahapan mulai tahap perencanaan, pengawasan, dan implementasi. Ilustrasi yang dikemukakan Wearing (2001) tersebut menegaskan bahwa masyarakat lokal berkedudukan sama penting dengan pemerintah dan swasta sebagai salah satu pemangku kepentingan dalam pengembangan pariwisata.

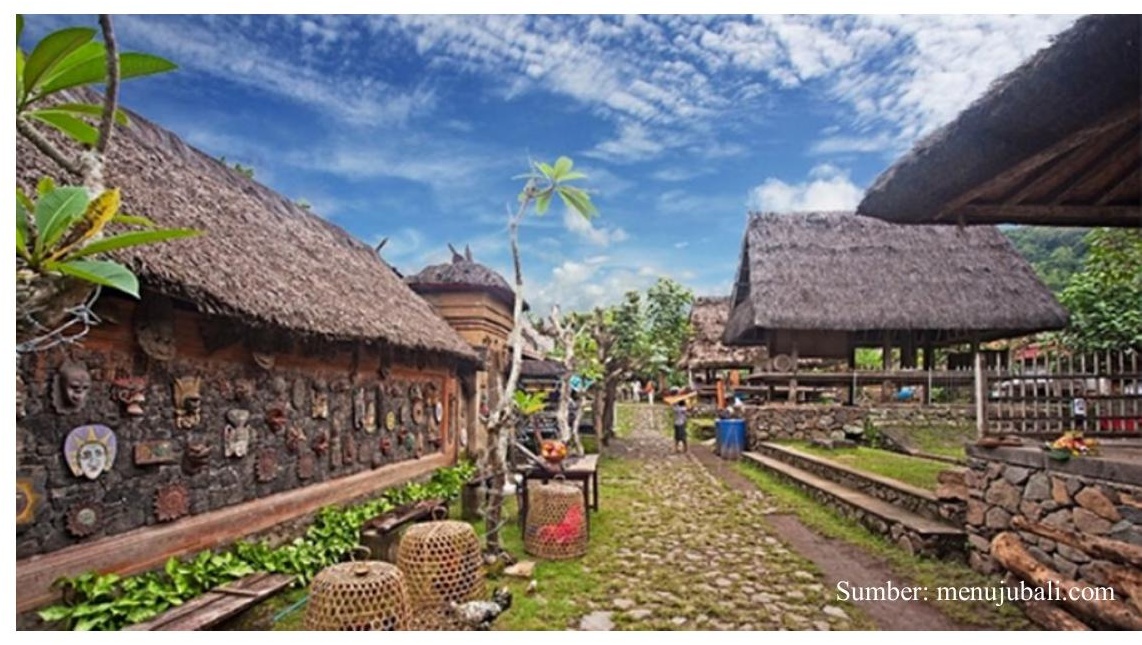




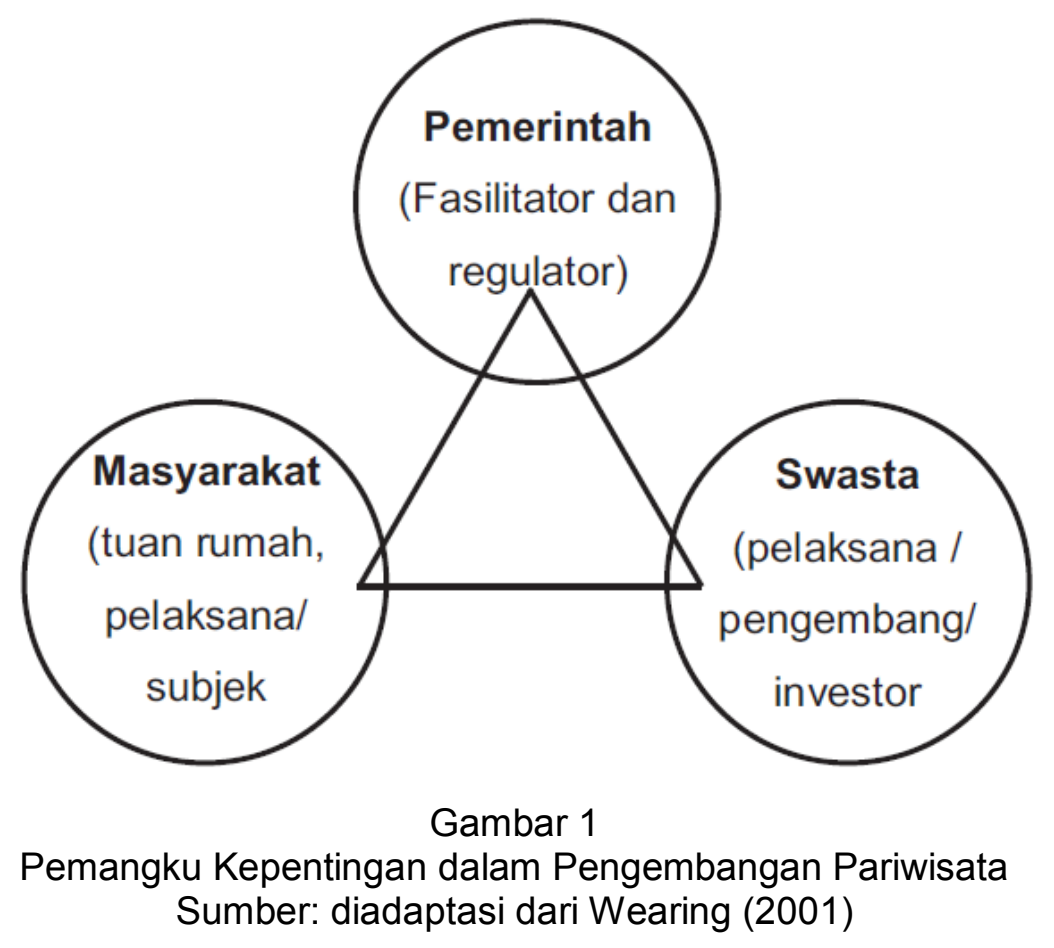

THK sebagai pedoman pengembangan konsep pembangunan pariwisata berbasis masyarakat dapat dijelaskan sebagai berikut.

\section{Pawongan}

Dalam pawongan, dilakukan pemberdayaan masyarakat lokal, peningkatan mutu sumber daya manusia, dan pembenahan aturan dari desa adat yang masih tergolong kaku untuk mendorong warganya agar lebih berprestasi tanpa ketakutan akan dikucilkan oleh desa adatnya sendiri

2. Palemahan

Dalam palemahan, dilakukan bisnis yang ramah lingkungan, mengutamanakan potensi ecotourism dari masing-masing kabupaten dengan tidak mengganggu keaslian alam itu sendiri, pemerataan pengetahuan tentang penerapan asas pelestarian lingkungan.

3. Parhyangan

Dalam parhyangan, dilakukan sosialisasi mengenai ajaran agama Hindu yang disesuaikan dengan Kitab Suci Weda, membangun dan memerbaiki pura-pura, dan mengadakan upacara-upacara keagamaan yang berupa: piodalan, pecaruan, ngenteg linggih, dan lainnya yang disesuaikan dengan hari baik. 
PENUTUP

Pembangunan berbasis masyarakat (community based tourism-CBT) merupakan model pembangunan yang memberikan peluang yang sebesar-besarnya kepada masyarakat pedesaan untuk berpartisipasi dalam pembangunan pariwisata. Inilah village tourism, yang dikenal dengan desa wisata di

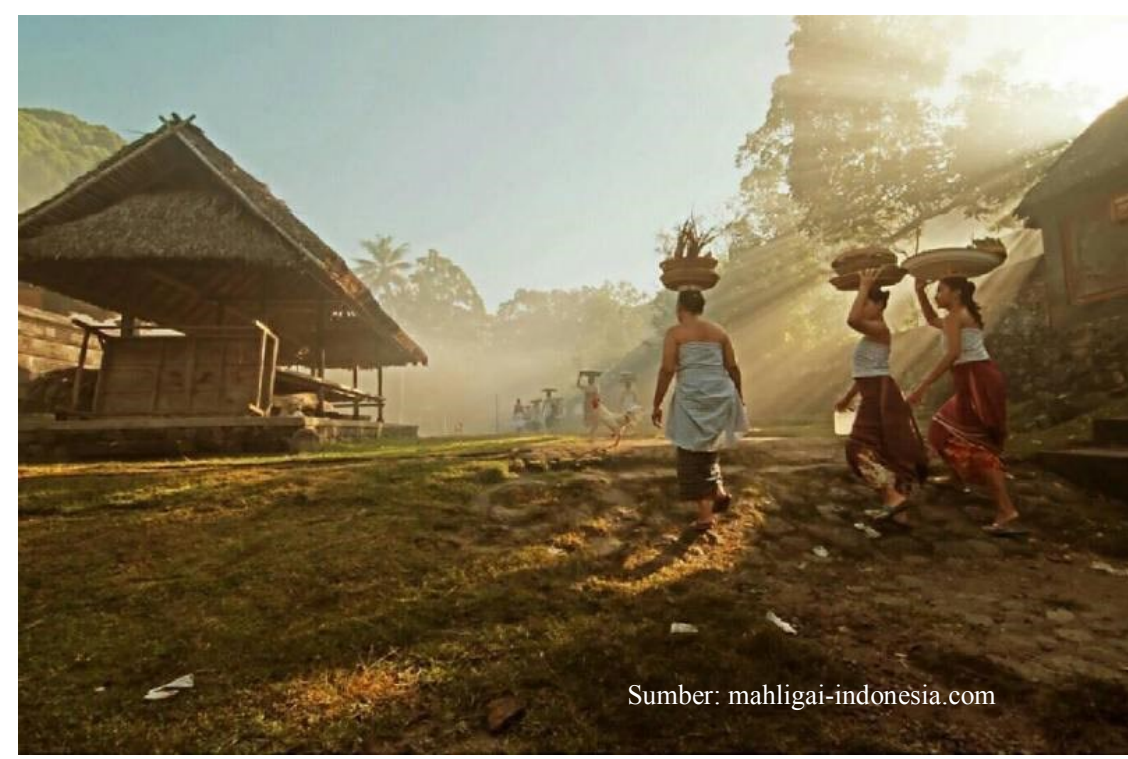
Indonesia daripada wisata desa.

CBT merupakan sebuah kegiatan pembangunan pariwisata yang dilakukan sepenuhnya oleh masyarakat. Ide kegiatan dan pengelolaan dilakukan seluruhnya oleh masyarakat secara partisipatif, dan manfaatnya dirasakan langsung oleh masyarakat lokal. Dengan demikian, dalam CBT peran masyarakat lokal sebagai pemangku kepentingan merupakan unsur terpenting dalam pengembangan desa wisata.

\section{REFERENSI}

Dinas Pariwisata Daerah Istimewa Yogyakarta. 2014. Laporan Akhir Kajian Pengembangan Desa Wisata di DIY.

Hadiwijoyo, Suryo S. 2012. Perencanaan Pariwisata Perdesaan Berbasis Masyarakat (Sebuah Pendekatan Konsep) 1st ed. Yogyakarta: Graha IImu.

http: //www.berdesa.com/apa-beda-desa-wisata-dan-wisata-desa/.

Wearing, S.L. and Donald, Mc. 2001. "The Development of Community Based Tourism: Re-Thinking The Relationsgip between Tour Operators and Development Agents as intermediaries in rural and isolated area Communities," Journal of Sustainable Tourism. 